\title{
Política antiterrorista y debate público, 1996-2009
}

\author{
Juan Avilés
}

Durante tres décadas, la amenaza terrorista ha sido una de las grandes preocupaciones de los españoles y ha sido un elemento central en el debate político, a través de sucesivas fases en las que el consenso entre los partidos democráticos ha alternado con la acritud polémica. Todo lo cual se explica no sólo por el número de víctimas causado por los atentados, sino por un rasgo del terrorismo en el que han insistido una y otra vez los analistas del fenómeno: su capacidad de alcanzar, a través del eco que sus acciones alcanzan en los medios de comunicación, un impacto político mucho mayor que el daño personal efectivamente causado.

No existe una definición del terrorismo universalmente aceptada y de hecho se trata de un término que tiene una fuerte carga polémica, pero una de las más difundidas lo describe como una «violencia premeditada, con motivación política, perpetrada contra objetivos no combatientes por grupos no estatales o por agentes clandestinos, habitualmente con el propósito de influir en una audiencia». ${ }^{1}$ El último rasgo de esta definición, el propósito de influir en una audiencia, se ha destacado muchas veces y la politóloga estadounidense Brigitte Nacos ha propuesto incluso el concepto de «terrorismo a través de los medios de comunicación» (mass-mediated terrorism) que define como «una forma de violencia política dirigida contra no combatientes, cuyo propósito es que se dé publicidad a sus actos para ganar la atención de la opinión pública y del gobierno». ${ }^{2}$ De hecho, el terrorismo representa una estrategia asimétrica que

1 Hoffman, Bruce, Inside terrorism, Indigo, 1999, p. 38. Sobre los problemas que plantea la definición del terrorismo: Merari, Ariel, «Terrorism as a strategy of insurgency», Terrorism and Political Violence, 5:4 (1993); Schmid, Alex P., «Frameworks for conceptualising terrorism», Terrorism and Political Violence, 16:2 (2004); Weigend, Thomas, «The universal terrorist: the international community grappling with a definition», Journal of International Criminal Justice, 2006.

2 Nacos, Brigitte L., Mass-mediated terrorism, 2002, p. 17. Sobre este tema: WiLkinson, 
permite compensar la debilidad de recursos de una organización frente a su enemigo, que suele ser un Estado, mediante el eco en la opinión que alcanzan sus atentados. ${ }^{3}$

En este ensayo examinaremos el debate en torno a la política antiterrorista de los presidentes Aznar y Rodríguez Zapatero, centrándonos en las posiciones mantenidas por el PP, el PSOE y sus respectivos apoyos mediáticos. La fuente utilizada ha sido necesariamente la prensa, al tratarse de un debate público. Hemos recurrido a El País para aquellas noticias que aparecían de modo similar en todos los medios de comunicación, mientras que hemos diversificado las fuentes cuando se trataba de mostrar diferentes puntos de vista.

\section{El primer gobierno de Aznar, el pacto de Lizarra y la tregua de ETA, 1996- 1999}

El recurso a la «guerra sucia», cuyo último episodio tuvo un gran impacto en el crispado debate político de los últimos años de gobierno de González, había quedado descartado de hecho a mediados de los años ochenta. ${ }^{4} \mathrm{~A}$ partir de entonces, el esfuerzo por poner fin al terrorismo de ETA sólo pudo seguir el camino de la aplicación de la ley a los terroristas, el camino de la negociación para lograr su desistimiento o una combinación de ambos. En términos generales el PP ha mostrado predilección por la primera vía y el PSOE por la segunda, pero con importantes oscilaciones. Aznar exploró brevemente la vía del diálogo en 1999 y Rodríguez Zapatero lo hizo con mayor perseverancia en 2006 y 2007, pero en ambos casos el acuerdo se mostró inviable porque ETA se mostró aferrada a su programa máximo, cuya aceptación resulta casi imposible en el contexto político español. Así es que tras la ruptura de la tregua por ETA en 2007, Zapatero retomó la línea de firmeza frente a ETA. Así es que se han sucedido periodos de consenso antiterrorista entre los dos grandes partidos, como el que llevó al pacto de 2002, y periodos de enfrentamiento frontal, sobre todo entre 2004 y 2007. Por otra parte en el debate político sobre el tema ha jugado siempre un papel destacado el PNV, que ha combinado la condena del terrorismo de ETA con el rechazo a muchas de las medidas legales adoptadas para derrotarla. ${ }^{5}$

Paul, «The media and terrorism: a reassessment», Terrorism and Political Violence, 9:2 (1997).

3 CRENSHAW, Martha, «The logic of terrorism: terrorist behaviour as a product of strategic choice», en Reich, W. (ed.), Origins of terrorism, Woodrow Wilson Center, 1990.

4 Woodsworth, Paddy, Guerra sucia, manos limpias: ETA, el GAL y la democracia española, Crítica, 2002.

5 Sobre el terrorismo de ETA: Domínguez, Florencio, ETA, estrategia organizativa y actuaciones, 1978-1992, UPV, 1998; Elorza, Antonio (coord.), La historia de ETA, Temas de Hoy, 
Cuando en mayo de 1996 José María Aznar formó su primer gobierno, con Jaime Mayor Oreja como ministro del Interior, el terrorismo de ETA representaba una de las mayores preocupaciones de los españoles. Quedaba ya lejos el periodo más terrible, el de los años 1978 a 1980 en que, coincidiendo con el debate constitucional y la puesta en marcha de la autonomía vasca, ETA asesinó a una media de ochenta personas por año. Durante el periodo de gobierno de Felipe González esa trágica media se había reducido a algo menos de treinta, pero ello resultaba suficiente para que en el País Vasco se mantuviera un ambiente sombrío en el que era necesario un gran valor para condenar abiertamente a ETA. Las primeras grandes movilizaciones ciudadanas contra el terrorismo se produjeron con ocasión del secuestro de los empresarios Julio Iglesias (1993) y José María Aldaya (1995). ${ }^{6}$ La respuesta de ETA a este desafío consistió en el acoso de quienes pedían su liberación por los militantes de Herri Batasuna, a quienes se permitía increpar a los manifestantes. ${ }^{7}$

Por otra parte la actividad policial contra ETA ganó en eficacia durante los años de gobierno de Felipe González, en los que las detenciones masivas de los primeros años de la Transición, que sólo en un pequeño porcentaje se traducían en condenas judiciales, dieron paso a una acción mucho más selectiva. ${ }^{8}$ Resultó además crucial el cambio de actitud del Gobierno francés, que puso fin a la impunidad con que ETA se movía en el territorio de la vecina república. ${ }^{9}$ Las primeras extradiciones de terroristas fueron concedidas por Francia en noviembre de 1984, aunque sólo se convirtieron en una práctica habitual desde finales de 1987, y en total 41 supuestos miembros de organizaciones terroristas, en su mayoría etarras, fueron extraditados por Francia hasta febrero de $2000 .{ }^{10}$ No menos importante fue el encarcelamiento de 253 terroristas españoles en Francia entre 1988 y 1997. Hasta 27 dirigentes de la banda fueron allí detenidos entre septiembre de 1987 y enero de 1997. ${ }^{11}$

Aznar heredó por tanto una situación menos dramática de la que había encontrado González, aunque ETA mantenía una notable capacidad de matar. En

2000; Reinares, Fernando, Patriotas de la muerte: quiénes han militado en ETA y por qué, Taurus, 2001; SÁnchez CuenCA, Ignacio, ETA contra el Estado: las estrategias del terrorismo, Tusquets, 2001; Calleja, J. M. y Sánchez Cuenca, I., La derrota de ETA, Madrid, 2006.

6 Funes Rivas, María José, La salida del silencio, movilizaciones por la paz en Euskadi, 19861998, Madrid, 1998.

7 El País, 15-4-1996.

8 Domínguez Iribarren, Florencio, De la negociación a la tregua, el final de ETA?, Madrid, 1998, pp. 196-221.

9 Morán, Sagrario, ETA entre España y Francia, Madrid, 1997.

10 El Correo Español, 9-2-2000.

11 El País, 18-1-1997.

Pasado y Memoria. Revista de Historia Contemporánea, 9, 2010, pp 149-166 
el plano político estaba vigente el pacto de Ajuria Enea, suscrito en enero de 1988 por todos los partidos democráticos vascos, que proclamaba como su objetivo común la erradicación del terrorismo. El Gobierno vasco, encabezado por el nacionalista José Antonio Ardanza, contaba con participación socialista y el propio Aznar estableció en sus primeros meses de gobierno una buena relación con el PNV.

El acuerdo de Ajuria Enea no había acabado sin embargo con la ambigüedad de los dirigentes peneuvistas, que combinaban la denuncia de los crímenes de ETA con la crítica a las medidas antiterroristas del Gobierno español y a veces dejaban ver su temor a que una derrota completa de ETA perjudicara al nacionalismo en su conjunto. Esa actitud tenía su exponente más distinguido en el propio presidente del PNV, Xavier Arzalluz, quien en una entrevista secreta que mantuvo en marzo de 1991 con dirigentes de KAS (en la que uno de los asistentes redactó un detallado informe, más tarde localizado durante un registro judicial y dado a conocer a la prensa) empleó una comparación que se ha hecho famosa. Dijo que ningún pueblo se había liberado jamás sin que unos sacudieran el árbol y otros recogieran las nueces (entiéndase: las acciones de ETA quebrarían la voluntad de resistencia del Estado español y el PNV podría negociar la soberanía). ${ }^{12}$ En público Arzalluz no era mucho más comedido y en un discurso de 1996, en el que criticó duramente tanto a los socialistas como a Aznar, lanzó esta pregunta retórica: «en el tema de ETA ¿qué molesta: el tiro, el asesinato, o la finalidad?». ${ }^{13}$

La ambigüedad nacionalista frente a ETA era compartida por un importante sector del clero vasco y notoriamente por el obispo de San Sebastián, José María Setién, quien en unas declaraciones de agosto de 1996 llevó su equidistancia hasta afirmar que el conflicto surgía de «una mutua deslegitimación, independiente de quien tenga en abstracto la razón, si España, que quiere la unidad del Estado español, o ETA, que quiere la independencia de Euskadi». ${ }^{14}$ En contraste con esta actitud clerical, más de 600 profesores de las universidades vascas y navarras suscribieron un manifiesto contra el terrorismo tras el asesinato de Francisco Tomás y Valiente en febrero de $1996 .{ }^{15}$ En conjunto la población vasca se mostraba en las encuestas muy contraria a ETA y las elecciones venían demostrando una y otra vez que su brazo político, Herri Batasuna, sólo tenía un apoyo minoritario, pero con todo no había desaparecido la imagen favorable

\footnotetext{
12 El Mundo, 24-9-2000.

13 El País, 25-11-1996.

14 El Diario Vasco, 13-8-1996.

15 El País, 1-3-1996.
} 
que en ciertos ámbitos habían llegado adquirir los etarras, que a mediados de los años noventa era compartida por casi el $25 \%$ de los vascos, proporción que se elevó hasta casi el 50\% cuando la organización terrorista se declaró en tregua en 1999. ${ }^{16}$

El gran estallido de repulsa contra ETA se produjo en 1997 tras el secuestro y asesinato del concejal del PP en Ermua, Miguel Ángel Blanco, que dio lugar a centenares de concentraciones en todo el País Vasco e inmensas manifestaciones en toda España. Hubo un acuerdo de todos los partidos democráticos para aislar a Herri Batasuna, que se tradujo en algunos acuerdos locales para desplazarla del poder municipal, y por unas semanas pareció que el clima político vasco iba a modificarse. No fue así, porque los nacionalistas se sintieron amenazados por aquella movilización popular. Años después un destacado intelectual nacionalista, Koldo San Sebastián, lo explico así en un artículo de prensa: «Días después del asesinato de Miguel Ángel Blanco, centenares de militantes del PNV nos reunimos en asamblea para ver como afrontábamos la brutal campaña mediáticopolítica que se había desatado contra nosotros. En las asambleas se produjeron momentos muy tensos. Había quien pensaba que, efectivamente, sin ETA nos convertiríamos en una fuerza vulgar.» ${ }^{17}$ Por su parte Arzalluz expresó lo que sentía: «en Madrid habrá aplausos cerrados viendo como los vascos nos destrozamos entre nosotros». ${ }^{18}$

Se produjo pues divergencia radical entre las actitudes del PP y el PSOE y las del PNV y el conjunto del nacionalismo vasco. La impunidad de que habían gozado las entidades asociadas a ETA comenzó por otra parte a desaparecer, como resultado de diversas iniciativa judiciales. En diciembre de 1997 el Tribunal Supremo condenó a siete años de cárcel a los miembros de la Mesa Nacional de Herri Batasuna por colaboración con banda armada, debido a que habían cedido sus espacios electorales a ETA en la campaña de 1996, a lo que el PNV replicó con la tesis de que esa sentencia criminalizaba la defensa de la independencia. ${ }^{19}$ Más tarde, cuando en julio de 1999 el Tribunal Constitucional anuló aquella decisión del Supremo, el portavoz del PNV en el Congreso de los Diputados, Iñaki Anasagasti, exigió la dimisión del ministro Mayor Oreja, quien según él habría impulsado las medidas contra $\mathrm{HB}$ «por venganza y no por justicia», de acuerdo con la estrategia nacionalista de atribuir al Gobierno el control de las decisiones

16 Departamento de Ciencia Política y Administración, UPV, Euskobarómetro, series temporales, mayo 2008, p. 46.

17 Deia, 24-7-2001.

18 Deia, 10-8-1997.

19 El País, 4-12-1997.

Pasado y Memoria. Revista de Historia Contemporánea, 9, 2010, pp 149-166 
judiciales contra los colaboradores de ETA. ${ }^{20}$

La inflexión en la actitud de la justicia frente al entramado civil de ETA se produjo con el cierre del diario Egin y de otras empresas vinculadas con la banda terrorista, que el juez Baltasar Garzón acordó en un auto de julio de 1998 en el que por primera vez sostuvo la tesis crucial de que ETA era una organización compleja, integrada no sólo por sus comandos terroristas, sino por un conjunto de entidades coordinadas por KAS y cuya expresión legal era Herri Batasuna. De nuevo en este caso, el PNV expresó su protesta. A estas alturas, ETA se encontraba pues en una situación difícil, amenazada en su antiguo refugio francés, sometida a la continua detención de sus miembros, y debilitada por la acción de la justicia contra su complejo entramado de entidades. A su vez el PNV daba claras muestras de temer que una derrota de ETA representara un revés para la causa independentista. Y por otra parte el acuerdo de paz de 1997 en Irlanda del Norte parecía ofrecer un modelo muy distinto para el fin del «conflicto». El resultado de todo ello fue el fin del acuerdo de Ajuria Enea, que dio paso al pacto de Lizarra.

La quiebra definitiva del pacto de Ajuria Enea se produjo como resultado del rechazo por parte del PP y el PSOE del llamado plan Ardanza de enero de 1998, que proponía dejar «la resolución dialogada del conflicto en manos de los partidos representativos de la sociedad vasca» (y relegaba por tanto al conjunto de España al papel de aprobar lo que aquellos decidieran) supuso ${ }^{21}$ que el 30 de junio de 1998, después de diversas votaciones en el parlamento autonómico que parecían responder a una nueva mayoría, formada por PNV, Eusko Alkartasuna, HB e Izquierda Unida, el PSOE abandonó el Gobierno de Vitoria, que quedó integrado por PNV y EA.

Según se supo más tarde, el acercamiento entre PNV y HB se había iniciado en diciembre de 1997 en un encuentro de Juan María Ollora y Joseba Egibar con Rufi Etxeberría y José María Olarra, poco antes del encarcelamiento de la Mesa Nacional de HB. ${ }^{22}$ En febrero de 1998 se celebró la primera reunión oficial entre las delegaciones del PNV y HB y en junio se puso en marcha el Foro de Irlanda que, con el propósito de analizar la relevancia del modelo norirlandés de pacificación, agrupó a todo el conjunto de organizaciones nacionalistas y a Izquierda Unida. Esta iniciativa que estuvo precedida por un encuentro directo entre PNV y ETA, pues ya en enero de 1998 dos etarras contactaron en Bruselas a un eurodiputado del PNV y le propusieron un acuerdo de todas las fuerzas nacionalistas

20 El Mundo, 20-7-1999.

21 El País, 12-3-1998.

22 El País, 20-9-1998.

Pasado y Memoria. Revista de Historia Contemporánea, 9, 2010, pp 149-166 
que podría dar lugar a una tregua de ETA..$^{23}$

El acuerdo se alcanzó en el verano de 1998 en encuentros entre delegados de ETA, PNV y EA, que al parecer se produjeron en Bélgica. El texto del acuerdo secreto que en agosto de 1998 suscribieron PNV, EA y ETA (significativamente sin participación de $\mathrm{HB}$, lo que prueba el escaso margen de autonomía que le concedía ETA) lo dio a conocer esta última a través del diario Gara, tras la ruptura de la tregua y su autenticidad ha sido confirmada por el PNV. Las tres organizaciones se comprometieron a dar pasos efectivos para la creación de una institución única y soberana que acogiera en su seno a «Araba, Bizcaia, Gipuzcoa, Lapurdi, Nafarroa y Zuberoa» (es decir la Comunidad Autónoma Vasca, Navarra y los territorios franceses de tradición vasca). PNV y EA se comprometieron a abandonar todos sus acuerdos con aquellas fuerzas cuyo objetivo era la destrucción de Euskal Herria y la construcción de España, es decir PP y PSOE, y ETA se comprometió a proclamar un alto el fuego indefinido. ${ }^{24}$.

El acuerdo comenzó a cumplirse a lo largo de los siguientes meses. El 12 de septiembre las organizaciones representadas en el Foro de Irlanda, suscribieron la declaración de Lizarra, el 16 ETA anunció la suspensión indefinida de sus acciones, el 29 de diciembre se constituyó el Gobierno exclusivamente nacionalista de Ibarretxe, con apoyo externo de HB, y el 6 de febrero de 1999 se constituyó la Asamblea de Municipios de Euskal Herría (Udalbitza). La declaración de Lizarra, suscrita por PNV, EA, HB, IU y otras entidades, proponía como solución al «contencioso vasco», la de «depositar en los ciudadanos de Euskal Herria la última palabra respecto a la confirmación de su futuro» (es decir el derecho de autodeterminación) y el respeto de su decisión "por parte de los Estados implicados» (es decir España y Francia). ${ }^{25}$

En las elecciones autonómicas del 25 de octubre de 1998 el conjunto del voto nacionalista aumentó respecto a las de 1994, en beneficio sobre todo de Euskal Herritarrok, la nueva marca electoral de HB, pero el partido que más avanzó fue el PP, mientras que el más castigado por sus electores fue IU. Así es que PNV y EA se encontraron sin mayoría parlamentaria propia y, puesto que el PSOE no iba a admitir los postulados de Lizarra, el nuevo gobierno de Juan José Ibarretxe sólo pudo formarse contando con la benevolencia de EH. Por su parte la Asamblea de Municipios representó un primer paso hacia el nuevo marco de territorialidad definido en Lizarra y previamente pactado con ETA, pero puso también de manifiesto la irrealidad del proyecto, pues sólo estuvieron

23 Crónica Vasco Press, 915, 30-8-1999.

24 <www.eaj-pnv.com/downloads/980730Doc1.jpg> [fecha de consulta: 28-12-2000].

25 El País, 13-9-1998. 
representados una minoría de los municipios navarros y de los territorios vascos de Francia y entre los de la Comunidad Autónoma Vasca que rechazaron su participación se hallaban los de Vitoria y San Sebastián.

Debe añadirse que la tregua no implicó el cese del terrorismo de baja intensidad ejercido por los grupos Y, la llamada kale borroka (lucha callejera), que al parecer habían reclamado PNV y EA en su propuesta de desarrollo del acuerdo con ETA. La kale borroka se mantuvo, aunque a un nivel más bajo que en años anteriores, mientras que las detenciones realizadas con este motivo por la Erzaintza se redujeron en proporción mucho mayor. La percepción generalizada fue que el mando político de la policía autónoma vasca procuraba evitar intervenciones que pudieran desagradar a sus nuevos aliados. Por su parte EH se negó a desautorizar la violencia callejera.

No sabemos si ETA se planteó la tregua como un simple respiro para reorganizarse o si realmente apostó por una vía política hacia la independencia. Lo que la organización terrorista sí ha explicado es que trataba de esclarecer la «ambigüedad histórica» del PNV. ${ }^{26}$ Tampoco sabemos si la denuncia del marco estatutario por parte de éste fue un movimiento táctico destinado a propiciar el abandono de las armas por ETA, a facilitarle una pista de aterrizaje como se dijo, o si lo que pretendía construir era una pista de despegue hacia la independencia (probablemente ambas cosas eran ciertas). Por su parte el Gobierno de Aznar trató de explorar la posibilidad de que la tregua de ETA pudiera convertirse en definitiva. El 19 de mayo de 1999 se produjo un encuentro entre representantes del Gobierno español y de ETA, en la que ésta exigió a aquél que aceptara el derecho de autodeterminación de Euskal Herría. ${ }^{27}$

La decepción de ETA ante la actitud de sus nuevos socios no tardó en producirse. En una reunión celebrada el 11 de julio la organización terrorista acusó a PNV y EA de no haber roto con España y de mantener abiertos los puentes con el PSOE y les anunció que suspendía el pacto alcanzado en agosto de 1998 y por tanto el alto el fuego ${ }^{28}$ Poco después ETA canceló el segundo encuentro que iba a tener con representantes del Gobierno español y, a fines de agosto, denunció en un comunicado la actitud tibia del PNV y la detención del proceso de construcción nacional. ${ }^{29}$. Finalmente, ETA anunció la ruptura de la tregua a finales de noviembre, con un comunicado en el que de nuevo acusaba a PNV y EA de pretender cambiar la naturaleza de la iniciativa pactada, convirtiendo el proceso

26 Gara, 30-4-2000.

27 El acta de la reunión redactada por ETA fue publicada en Gara, 1-5-2000 y los interlocutores identificados en El País, 2-5-2000.

28 Gara, 29-4-2000.

29 El Correo Español, 29-8-1999. 
de construcción nacional en un proceso de paz sin contenido, y de pretender ahogar a la izquierda abertzale en la normalidad política. ${ }^{30}$ Pero, a pesar de la ruptura de la tregua, el PNV no modificó su compromiso con el pacto de Lizarra y en un comunicado afirmó que el proceso emprendido era irreversible. ${ }^{31}$ Aznar denunció en términos muy duros esta estrategia del PNV. ${ }^{32}$

\section{LA OFENSIVA LEGISLATIVA Y JUDICIAL CONTRA ETA, 2000-2003}

ETA reanudó su actividad homicida en febrero de 2000, con el asesinato del dirigente socialista vasco Fernando Buesa y de su escolta. Un mes después Aznar ganó por segunda vez unas elecciones generales y en ellas el PP fue el segundo partido más votado en el País Vasco, donde obtuvo los mejores resultados de su historia. La segunda legislatura de Aznar se caracterizó por una enérgica actuación contra ETA, como resultado de la cual la banda, que en total asesinó a setenta personas entre 1996 y 2003, es decir casi nueve al año, sufrió un fuerte deterioro. En el periodo citado, fueron detenidos un millar de miembros o colaboradores de ETA: 634 en España, 331 en Francia y 40 en otros países. ${ }^{33}$ Entre ellos se encontraban once dirigentes de sus aparatos político, militar y logístico. ${ }^{34}$

En el plano legislativo, el parlamento español aprobó tres medidas importantes que facilitaron la lucha contra ETA y su entorno. En noviembre de 2000 el Congreso de los Diputados aprobó, con sólo 14 votos en contra, el primer trámite de un proyecto de reforma del Código Penal y de la Ley Penal del Menor, que endureció las penas en los casos de kale borroka. ${ }^{35}$ El PSOE apoyó esta medida, que recibió en cambio durísimas críticas en medios nacionalistas, hasta el punto de que un colaborador de Deia llegó a afirmar que la reforma transparentaba «un verdadero odio político hacia lo vasco». ${ }^{36}$ Lo cierto es que la kale borroka, protagonizada por jóvenes e incluso por menores, no sólo amplificaba el temor causado por los atentados de la propia ETA, sino que, al no ser combatida con efectividad por la policía autónoma vasca, producía una sensación de impunidad y se convertía en cantera de futuros etarras. El País se refirió a los borrokas como «cachorros de ETA»y ABC los calificó de «hijos de la impunidad». ${ }^{37}$ El efecto de esta reforma legislativa no tardó en manifestarse, pues el número de incidentes

30 El País, 29-11-1999.

31 El País, 3-12-1999.

32 El País, 7-12-1999.

33 El País, 30-1-2004.

34 El País, 19-4-2009.

35 El País, 17-11-2000.

36 Álunarez Solís, Antonio, Deia, 14-9-2000.

37 El País, 27-8-2000. ABC, 27-8-2000. 
de violencia callejera en el País Vasco y Navarra se redujo de 581 en 2000 a 150 en 2003. ${ }^{38}$

La segunda medida legislativa que reforzó la lucha contra ETA se adoptó en marzo de 2003, cuando el Congreso de los Diputados aprobó, con sólo 16 en contra y de nuevo con el apoyo del PSOE, el primer trámite de otra reforma del Código Penal que endureció las penas por terrorismo, ampliando la máxima de 30 a 40 años. La posibilidad de que terroristas que hubieran asesinado a numerosas personas pudieran ser puestos en libertad tras sólo 20 años, prevista por el Código de 1995, quedó anulada. ${ }^{39}$ Pero la medida legislativa más importante del periodo, que puso fin a la extraordinaria situación en la que una misma fuerza, integrada por ETA, HB y demás entidades del entramado terrorista, pudiera actuar libremente, participar en elecciones, recibir subvenciones y al mismo tempo asesinar a sus oponentes, fue la Ley de Partidos que el Congreso de los Diputados aprobó en junio de 2002. Este proyecto de ley, que abría la posibilidad de que fueran ilegalizadas formaciones políticas como Batasuna, fue aprobado en el Congreso por 304 votos contra 16. Votaron a favor PP, PSOE, CIU, Coalición Canaria y Partido Andalucista, y en contra IU, PNV, EA y BNG. ${ }^{40}$ Previamente, el Parlamento vasco había mostrado su rechazo de la ley, con la oposición de PP y PSOE. ${ }^{41}$

Paralelamente a este impulso legislativo, el juez Baltasar Garzón llevó a cabo numerosas iniciativas para desarticular todo el entramado de entidades que ETA había creado, en concreto Ekin, Xaki, Haika y su sucesora Segi, las Gestoras pro Amnistía, las herriko tabernas y finalmente Batasuna. En septiembre de 2000 Garzón encarceló a los principales dirigentes de Ekin, la coordinadora que había sustituido a KAS, y en marzo de 2001 la ilegalizó, bajo la acusación de formar parte de la estructura política de ETA, ejercer el control de los presos de la banda y planificar la kale borroka. En marzo de 2001 ordenó la clausura de la entidad legal Xaki, considerada como el instrumento de ETA en el plano de las relaciones internacionales. La organización juvenil Haika, considerada un apéndice de ETA, fue ilegalizada en mayo de 2001 y en diciembre de ese mismo año lo fueron las Gestoras pro Amnistía, otro componente del entramado etarra. ${ }^{42}$ En abril de 2002 fue ilegalizada la organización juvenil Segi, continuadora de Haika e impulsora de la kale borroka, y en mayo hubo una operación contra algunas herriko tabernas, que según el auto de Garzón eran utilizadas para la captación de

\footnotetext{
38 El País, 30-1-2004.

39 El País, 7-3-2003.

40 El País, 5-6-2002.

41 El País, 18-5-2002.

42 El País, 6-5-2002.
}

Pasado y Memoria. Revista de Historia Contemporánea, 9, 2010, pp 149-166 
nuevos militantes, el depósito de armas y explosivos para los atentados de ETA, la elaboración de artefactos para la kale borroka y la recopilación de información sobre posibles objetivos, todo ello bajo la dependencia directa de Batasuna. ${ }^{43} \mathrm{La}$ respuesta de los nacionalistas ante estas medidas judiciales fue marcadamente hostil. Tras la detención de los dirigentes de Haika un comunicado oficial del PNV la calificó de «nueva garzonada». ${ }^{44}$

Finalmente, en agosto de 2002, le tocó el turno al brazo político de ETA: el Congreso de los Diputados acordó, de nuevo por amplísima mayoría, instar al Gobierno para que presentara ante el Tribunal Supremo la demanda de ilegalización de Batasuna. ${ }^{45}$ La reacción del nacionalismo vasco fue entonces durísima y Arzalluz declaró que Euskadi estaba sufriendo un estado de excepción. ${ }^{46}$ No faltó tampoco a Batasuna el apoyo de la Iglesia vasca, pues en mayo de 2002 los obispos de Bilbao, San Sebastián y Vitoria difundieron una pastoral conjunta en la que expresaron su preocupación porque la aplicación de la Ley de Partidos pudiera afectar negativamente a la convivencia y la paz. La reacción que provocó este singular documento fue muy dura y El País, por ejemplo, se refirió a sus autores como «obispos nacionalistas». ${ }^{47}$ Pero lo más llamativo fue que la Conferencia Episcopal española salió en defensa de la polémica pastoral, en un documento que según El Mundo rezumaba «soberbia y desafío». ${ }^{48}$ Meses después, sin embargo, el cardenal Rouco impulsó una instrucción pastoral que denunciaba el terrorismo de ETA. ${ }^{49}$

Al mismo tiempo que el Congreso de los Diputados acordaba solicitar la ilegalización de Batasuna en aplicación de la Ley de Partidos, el juez Baltasar Garzón comenzó por su parte unas actuaciones encaminadas a su ilegalización, basándose en la legislación preexistente. El 20 de agosto de 2002 inició un sumario contra HB por integración en organización terrorista y el 26 suspendió por tres años sus actividades. En su extenso auto, basado en datos ya conocidos y en otros inéditos proporcionados por las fuerzas de seguridad, el juez argumentaba que Herri Batasuna había sido instrumentalizada y controlada por ETA desde su fundación en $1978 .{ }^{50}$

Esta ofensiva contra el entorno de ETA irritó profundamente al sector más

43 El País, 5-7-2002.

44 El País, 7-3-2001.

45 El País, 27-8-2002.

46 El País, 7-9-2002.

47 El País,1-6-2002.

48 El Mundo, 7-6-2002.

49 El País, 23-11-2002.

50 El País, 27-8-2002 y 28-8-2002.

Pasado y Memoria. Revista de Historia Contemporánea, 9, 2010, pp 149-166 
radical del nacionalismo democrático. En una entrevista que concedió a un periódico polaco en el verano de 2001, Arzalluz explicó que la democracia española era de muy baja calidad, pero que a pesar de esto era posible actuar en ella y que por eso ETA era un estorbo muy perjudicial para el objetivo de la independencia por el que decía luchar. Según él, Aznar había confiado en que «los vascos» nunca podrían unirse porque existía ETA, pero se alarmó por las consecuencias políticas de la tregua: «Por eso no interesó que ETA dejara de matar. Y Mayor Oreja y Aznar hicieron lo posible para que ETA siguiera existiendo». En cambio, para los nacionalistas la solución del problema de ETA era primordial, aunque sólo fuera "por los presos, sus padres, sus familias», todos los cuales eran «de aquí». Esta última observación es crucial para entender a Arzalluz, pues transparentaba su concepción de la nación vasca: los etarras y sus familias pertenecían a ella, mientras que las víctimas vascas de ETA, a las que no aludía en la entrevista, al no ser nacionalistas no eran realmente «de aquí». El fin de ETA sólo podría lograrse mediante una negociación. ${ }^{51}$

Por su parte Aznar se mostraba entonces durísimo con el PNV y llegó a comparar la Euskadi de Arzalluz con la Serbia de Milosevic. ${ }^{52}$ En octubre de 2000 el PP consiguió que la Internacional Demócrata Cristiana expulsara de su seno al PNV, lo que demostró el desprestigio internacional en el que éste había caído desde su acuerdo con ETA en $1998 .{ }^{53}$ En España se acusaba al Gobierno de Ibarretxe de imponer a la Ertzaintza una pasividad frente al terrorismo de ETA y frente a la kale borroka que desmoralizaba a sus propios agentes. ${ }^{54} \mathrm{El}$ contraste con lo que ocurría en Navarra era llamativo: en 1999 esta comunidad sólo sufrió el $11 \%$ de las acciones de kale borroka, pero allí se efectuaron el $51 \%$ de las detenciones de borrokas. ${ }^{55} \mathrm{El}$ consejero de Interior Javier Balza ordenó en cambio intervenir a la policía autónoma contra los manifestantes que protestaban en San Sebastián por el atentado que estuvo a punto de costar la vida al socialista José Ramón Recalde, una actuación que fue considerada vergonzosa por el mayor sindicato de la Ertzaintza. ${ }^{56}$

Cuando el Tribunal Supremo acordó finalmente la ilegalización de Batasuna, en marzo de 2003, el Gobierno vasco acudió a instancias europeas. En septiembre de ese año demandó al Estado español ante el Tribunal Europeo de Derechos Humanos de Estrasburgo, acusándole de haber vulnerado derechos fundamen-

\footnotetext{
51 El País, 4-8-2001.

52 El País, 30-10-2000.

53 ABC, 11-10-2000.

54 El País, 12-8-2001.

55 El País, 10-4-2000.

56 El País, 19-11-2000.
}

Pasado y Memoria. Revista de Historia Contemporánea, 9, 2010, pp 149-166 
tales en la Ley de Partidos. ${ }^{57}$ No era ésta sin embargo la opinión dominante en Europa, pues en junio de 2003 los ministros europeos de Justicia e Interior acordaron por unanimidad la inclusión de Batasuna en la lista de organizaciones terroristas de la Unión Europea. ${ }^{58}$ Unos meses después, en febrero de 2004, el Tribunal de Estrasburgo rechazó la demanda del Gobierno vasco.

Esta actitud del PNV empujó al PSOE, que había abandonado el Gobierno de coalición con los nacionalistas en 1998, a un acercamiento hacia el PP, aunque esto acabó por generar graves disensiones internas. Tras el asesinato del dirigente socialista alavés Fernando Buesa, con el que ETA reanudó su actividad criminal en febrero de 2000, el lehendakari Juan José Ibarretxe declaró formalmente roto el pacto con Euskal Herritarrok, la nueva marca de Batasuna, pero el desencuentro entre nacionalistas y socialistas no tardó en hacerse visible en la propia manifestación de repulsa por el asesinato, en la que fue imposible un lema común y que los nacionalistas convirtieron en un acto de adhesión a Ibarretxe frente a las críticas recibidas. ${ }^{59}$ En abril el secretario general del PSE, Nicolás Redondo, declaró que no era posible conectar con el PNV, mientras que con el PP coincidían «en la defensa de las reglas del juego constitucionales y estatutarias», y añadió que sería muy sano que el futuro lehendakari no fuera nacionalista. ${ }^{60}$ Poco después propuso públicamente a Aznar un pacto antiterrorista. ${ }^{61}$

Los socialistas estaban en realidad divididos, tanto en el País Vasco como en el resto de España. El socialista catalán Ernest Lluch destacó en la promoción de un entendimiento con los nacionalistas vascos, pero ETA le asesinó en noviembre de 2002. La masiva manifestación de protesta que se celebró en Barcelona se convirtió en una exigencia de diálogo dirigida a Aznar. La periodista Gemma Nierga, que leyó la declaración conjunta, le añadió la siguiente conclusión, que generó malestar en el PP: «Estoy convencida de que Ernest hubiera intentado dialogar hasta con la persona que le mató. Ustedes que pueden, dialoguen por favor». ${ }^{62}$ El rector de la Universidad del País Vasco, Manu Montero, que participó en la manifestación, quedó tan impresionado por el sesgo que ésta tomó como para pronunciar unos meses después esta frase terrible: «En Barcelona tuve la sensación de manifestarme a favor del asesino de Lluch».63

Un mes después PP y PSOE formalizaron un pacto antiterrorista, en el que

\footnotetext{
57 El País, 10-9-2003.

58 El País, 6-6-2003.

59 El País, 23-2-2000 y 27-2-2000.

60 El Diario Vasco, 9-4-2000.

61 El País, 14-6-2000.

62 El Periódico, 24-11-2000.

63 El Periódico, 18-2-2001.
} 
manifestaron su propósito de eliminar del ámbito de la legítima confrontación entre ambos las políticas para acabar con el terrorismo. A diferencia del pacto de Ajuria Enea de 1988, el texto del acuerdo no contemplaba la posibilidad de un final dialogado de la violencia, sino que se planteaba como único objetivo la derrota del terrorismo. ${ }^{64}$ La dirección del PNV rechazó frontalmente este acuerdo y planteó la siguiente cuestión retórica: «¿Con quién se quiere acabar, con ETA o con el nacionalismo vasco?». ${ }^{65}$

El acercamiento entre las posiciones de los dos grandes partidos españoles respecto al conflicto vasco culminó en las elecciones autonómicas vascas de mayo de 2001, de las que se esperaba un cambio de mayoría. No fue así, pues el PNV y sus aliados consiguieron un número de escaños que les permitiría gobernar contando con la benevolencia de Euskal Herritarrrok. El PP aumentó sus votos y mantuvo su posición de segundo partido del parlamento vasco, mientras que el PSE se quedó estancado. La estrategia de Redondo no había dado réditos electorales y muy pronto surgieron las críticas contra su gestión. Desde El País Juan Luis Cebrián criticó con virulencia «la batalla verbal -y no sólo verbal- que desde el nacionalismo español se había entablado contra el nacionalismo vasco», con el «aplauso ancilar» de Redondo. ${ }^{66}$ Poco después un debate en el comité federal del PSOE estuvo marcado por numerosas intervenciones que exigían un alejamiento respecto a las posiciones del PP en el País Vasco. «La retórica guerrera de españolismo rancio de Aznar se ha estrellado contra la realidad», opinó por ejemplo Pascual Maragall, el presidente de los socialistas catalanes. ${ }^{67}$ En diciembre de ese mismo año, Redondo presentó su dimisión como secretario general del Partido Socialista de Euskadi y en marzo de 2002 el congreso del PSE, en el que Patxi López fue elegido secretario general, sancionó la ruptura con la línea de entendimiento con el PP. ${ }^{68}$

\section{El imPaCto POLÍTICO DEL 11-M}

El pacto antiterrorista de 2000 no mantuvo su efectividad durante muchos años. Cuando José Luis Rodríguez Zapatero inició en 2006 un proceso de negociación con ETA, fue objeto de una formidable campaña de descrédito por parte del PP y de sus medios afines. A ello contribuyó la extendida convicción de que la victoria socialista en las elecciones del 14 de marzo de 2004 se había basado en el

\footnotetext{
64 El País, 9-12-2000.

65 Deia, 13-12-2000.

66 El País, 18-5-2001.

67 El País, 20-5-2001.

68 El País, 25-3-2002.
}

Pasado y Memoria. Revista de Historia Contemporánea, 9, 2010, pp 149-166 
aprovechamiento de los atentados del 11 y que la versión oficial de los mismos no resultaba satisfactoria. Desde algunos medios de comunicación conservadores se difundieron los argumentos más inverosímiles para cuestionar la investigación judicial, en un ejemplo clásico de cómo una teoría de la conspiración infundada puede ser ampliamente aceptada, con resultados desastrosos para el rigor del debate político.

En la génesis de la teoría de la conspiración del 11-M el elemento crucial fue el resultado político de los atentados. José María Aznar había gobernado durante ocho años, con un balance muy positivo en opinión de sus electores, y las encuestas hacían probable una victoria del PP en las elecciones del 14 de marzo. Pero en los tres días que precedieron a las elecciones se produjeron los atentados, el Gobierno defendió la probable autoría de ETA, las primeras pruebas y detenciones apuntaron hacia los yihadíes y el recuerdo de la campaña contra la guerra de Irak se actualizó, provocando una movilización de electores de izquierda que contribuyó a la victoria del PSOE. ${ }^{69} \mathrm{La}$ encuesta postelectoral del CIS hace suponer que los atentados del 11-M pudieron incrementar en cerca de un millón de votos la diferencia entre PSOE y PP, una diferencia que finalmente fue de 1.350 .000 votos. $^{70} \mathrm{~A}$ partir de aquí pudo activarse una de las líneas de razonamiento más típicas de las teorías de la conspiración: quien se beneficia de los resultados de un crimen siempre es sospechoso. ${ }^{71}$

La versión oficial del 11-M, la que se desprende de toda la inmensa masa de pruebas acumuladas durante una exhaustiva investigación sostiene la culpabilidad de un grupo de terroristas yihadíes. ${ }^{72}$ La teoría de la conspiración, en cambio, presenta a los yihadíes como meros ejecutores, como mucho, y postula la existencia de otros conspiradores que los habrían utilizado. Inicialmente se insinuó una participación de los servicios secretos marroquíes, o incluso de los

69 Sobre el impacto electoral de los atentados: Noya, Javier, «Del 11-M al 14-M: estrategia yihadista, elecciones generales y opinión pública», Real Instituto Elcano, ARI, 2004; MICHAVILA, Narciso, «Guerra, terrorismo y elecciones: incidencia electoral de los atentados islamistas en Madrid», Real Instituto Elcano, DT, 2005; OlmedA, José A., «Miedo o engaño: el encuadramiento de los atentados terroristas del 11-M en Madrid y la rendición de cuentas electoral», Real Instituto Elcano, DT 2005.

70 CIS, Encuesta postelectoral, 1 14-3-2004 (estudio 2559).

71 Sobre la lógica de las teorías de la conspiración: Keeley, Brian L., «Of conspiracy theories», The Journal of Philosophy, XCVI.3 (1999); Clarke, Steve, "Conspiracy theories and conspiracy theorising», Philosophy of the Social Sciences, 32:2 (2002).

72 Jordán, J., MAÑAS, F. y Horsburg, N., «Strengths and weaknesses of grassroot jihadist networks: the Madrid bombings», Studies in Conflict and Terrorism, 31:1 (2008); ReinARES, Fernando, «Jihadist radicalisation and the 2004 Madrid bombing network», CTC Sentinel, 2:11 (2009); Avilés, Juan, «Los atentados del 11-M y el movimiento yihadista global», Historia del Presente, 14 (2009). 
franceses..$^{73}$ Sin embargo el culpable en el que habitualmente se pensaba era ETA, que fue inicialmente designada por el Gobierno de Aznar como principal sospechosa. A partir de ahí entró en acción la tendencia de las teorías de la conspiración injustificadas a implicar a más y más agentes en su red de sospechas. ¿Si ETA es culpable, por qué no se ha podido demostrar su culpabilidad a lo largo de toda la exhaustiva investigación realizada? La lógica conspirativa llevaba a suponer que ello se debía a la falta de interés en demostrarla por parte de los jueces, fiscales y agentes de las fuerzas de seguridad del Estado que se habían encargado de ello. El diputado popular Jaime Ignacio del Burgo, por ejemplo, puso en duda, entre otros extremos, que se hubieran suicidado los terroristas muertos en Leganés, tal como sostenían los informes policiales. ${ }^{74}$ Hubo incluso quien planteó la sospecha de que el propio Gobierno de Zapatero pudiera no estar interesado en que se probara la culpabilidad de ETA, pues ello pondría en entredicho la legitimidad moral de su victoria electoral y haría imposible la política de negociación con la banda terrorista que inició en 2006. En la campaña de denuncia de esa política subyacía la idea de que el Gobierno estaba dispuesto a hacer concesiones a una banda terrorista que había facilitado su acceso al poder. Así en la masiva manifestación que se celebró en Madrid el 10 de junio de 2006, convocada por la Asociación de Víctimas del Terrorismo, los dos lemas de la convocatoria fueron «iQueremos saber la verdad!» y «Negociación, en mi nombre, ¡no!». ${ }^{75}$

Los medios «conspiracionistas» no ofrecieron sin embargo una teoría plenamente perfilada, sino unos argumentos que ponían en duda la versión oficial, trataban de implicar a ETA y se limitaban a insinuar la posibilidad de una trama en la que participaran otros agentes, como ocurría en los artículos que bajo el título genérico de «Los agujeros negros del 11-M» publicó El Mundo a partir de abril de $2004 .{ }^{76}$ La crítica de las pruebas oficiales se centró en parte en detalles técnicos, como los rastros de componentes que dejan distintos tipos de explosivos sobre los que sólo unos pocos especialistas están en condiciones de opinar. Sin embargo hay un punto esencial en la argumentación «conspiracionista» sobre el cual puede formarse una opinión cualquier persona capaz de razonamiento desapasionado. Se trata de la bolsa recogida en la estación del Pozo e identificada horas después en la comisaría del Puente de Vallecas, que contenía la única bomba supuestamente colocada por los terroristas en los trenes que ni explotó

\footnotetext{
73 El Mundo, 28-3-2004

74 El Mundo, 17-4-2006.

75 ABC, 11-6-2006.

76 MúgicA, F., El Mundo, 18-4-2004.
} 
ni fue explotada más tarde por los Tedax y que, a través de las pistas proporcionadas tanto por el explosivo y el detonador que contenía, como por el teléfono móvil que habría debido poner en acción el detonador, como por la tarjeta del mismo, resultó crucial en los primeros momentos de la investigación. La tesis de los «conspiracionistas» es que esa bolsa era una pista falsa. Ello respondía a un rasgo típico de las teorías de la conspiración, el de centrar la atención en mínimos detalles de los que se pretende sacar grandes conclusiones: si no hay absoluta certeza de que la bolsa en cuestión se encontró en el tren, entonces es posible que no fuera depositada por los terroristas, sino por obra de un maquiavélico y desconocido agente que quería orientar la investigación.

Lo importante es que las pistas proporcionadas por aquella bolsa encajan perfectamente con las demás pruebas: el detonador lleva a la mina asturiana en la que sin duda los procesados adquirieron un explosivo idéntico al de la bolsa, y el teléfono móvil y su tarjeta llevan también hacia ellos. Llama por otra parte la atención el desdén con que los «conspiracionistas» se refieren a la capacidad operativa de «los moros de Leganés», a pesar del enorme impacto global que ha tenido el terrorismo yihadí a partir de los atentados de 2001.77

La mayor parte de los «conspiracionistas» no van más allá de incriminar a ETA y sembrar dudas sobre la versión oficial. Muy pocos se han atrevido a apuntar directamente hacia otros presuntos culpables. Sin embargo, como demuestra el caso de la bolsa de la estación del Pozo, si aceptamos la tesis conspiracionista hemos de concluir que existió una trama oculta capaz de seguir, o presumiblemente guiar, los pasos de los terroristas yihadíes y situar en el lugar adecuado pruebas que los incriminen, sin dejar el más mínimo rastro de su actuación. ¿De verdad se puede creer que ETA habría sido capaz de ello por sí sola? Una vez más, la perversa lógica de las teorías de la conspiración conduce a ampliar la supuesta trama y buscar nuevos culpables. Hace falta ser muy insensato para llevar la lógica conspirativa hasta el final, pero algunos lo han hecho. En junio de 2004 un editorial del diario El Mundo llevaba por título «Graves indicios de connivencia policial con la trama auxiliar del $11-\mathrm{M} »{ }^{78} \mathrm{Y}$ dos años después, en los micrófonos de la COPE, Federico Jiménez Losantos aludió a «la implicación

77 Sageman, Marc., Understanding terrorist networks, University of Pennsylvania Press, 2004; Reinares, F. y Elorza, A. (eds.), El nuevo terrorismo islamista, Temas de Hoy, 2004; Cook, David, Understanding yihad, University of California Press, 2005; Vidino, Lorenzo, Al Qaeda in Europe: the new battleground of international jihad, Prometheus Books, 2006; Corte Ibáñez, L. y Jordán, J., La yihad terrorista, Síntesis, 2007; Pargeter, Alison, The new frontier of jihad: radical Islam in Europe, I. B. Tauris, 2008; SAGEMAN, Marc, Leaderless jihad: terror networks in the twenty-first century, University of Pennsylvania Press, 2008.

El Mundo, 10-6-2004.

Pasado y Memoria. Revista de Historia Contemporánea, 9, 2010, pp 149-166 
de los servicios españoles de la Policía, de la Guardia Civil», aunque en otras ocasiones se ha mostrado algo más prudente: «casi mejor que sean los etarras los que hayan ayudado a los moros o los hayan llevado porque la otra alternativa son los servicios secretos españoles». ${ }^{79}$

\section{RODRÍGUEZ ZAPATERO, DE LA NEGOCIACIÓN A LA FIRMEZA, 2005-2009}

La decisión del gobierno Zapatero de explorar de nuevo la posibilidad de negociar con ETA una salida al conflicto recibió el respaldo del Congreso de los Diputados mediante una declaración de mayo de 2005, suscrita por todos los grupos salvo el PP, que autorizaba al Gobierno a entablar un diálogo con ETA si ésta cesaba en su actividad terrorista. Este diálogo versaría sólo sobre el futuro de sus presos y exiliados, pues las cuestiones políticas deberían ser debatidas exclusivamente por los partidos. Se trataba de un retorno a la posición planteada en el pacto de Ajuria Enea de 1988, que había sido abandonada en el pacto antiterrorista de 2000. No suponía sin embargo una ruptura formal con este último, pues se excluía la negociación política con ETA, que PP y PSOE se habían comprometido a evitar. En realidad esto implicaba que la negociación política se llevaría acabo con Batasuna.

Para entonces, los contactos ya estaban en marcha. Según un periodista de El País generalmente muy bien informado, el dirigente socialista vasco Jesús Eguiguren había tenido sucesivos encuentros con Otegi desde 2002, en los que convinieron en que el proceso debería avanzar por una doble vía, por un lado mediante la negociación entre el Gobierno español y ETA para el tema de presos y exiliados y por otro entre los partidos vascos para los temas políticos. En agosto de 2004, ETA remitió al Gobierno español una carta que proponía «establecer vías de comunicación para resolver el conflicto». Y en noviembre de ese año, en la asamblea de Anoeta, Otegi hizo pública la propuesta de que la negociación se desarrollara en dos mesas y que en la de carácter político ETA aceptara ser representada por Batasuna. Hubo un acuerdo para que en la negociación entre el Gobierno y ETA participara como mediador el Centro de Diálogo Henri Dunant, con sede en Ginebra. Y fue en Ginebra donde en junio de 2005, un mes después de la resolución parlamentaria que lo autorizaba, tuvo lugar el primer encuentro, protagonizado por Eguiguren, en contacto con el entonces portavoz socialista Alfredo Pérez Rubalcaba que controlaba la negociación desde Madrid, y por el veterano dirigente etarra Josu Urrutikoetxea, más conocido como Josu Ternera. El 14 de julio ambos llegaron a un acuerdo y ETA se comprometió a un alto el

79 Citado en $A B C$, 9-6-2006 y 5-10-2006. 
fuego y ese verano Zapatero informó a Rajoy de esos contactos. Una segunda tanda de reuniones tuvo lugar en noviembre en Oslo y los últimos detalles del acuerdo fueron perfilados por Eguiguren y Ternera en diciembre, de nuevo en Ginebra. El Gobierno exigió el compromiso de que ETA renunciara efectivamente a su actividad, incluidas la extorsión y la kale borroka, y se comprometió a que, si así era, se relajaría la actividad policial y Batasuna podría acogerse a la legalidad. Sobre estas bases, ETA anunció por fin un «alto el fuego permanente» el 22 de marzo de $2006 .{ }^{80}$

La versión que dio a conocer el diario afín a ETA Gara coincide en lo sustancial con la que El País había publicado, aunque incluye algún matiz interesante, como el acuerdo de que en caso de producirse «accidentes», es decir incumplimientos puntuales de las garantías pactadas, éstos deberían resolverse en la mesa de negociación. El acuerdo daba a Zapatero seis meses a partir del alto el fuego para realizar una declaración institucional sobre el tema, tiempo en el que, según Gara, debía lograr un «pacto de Estado» que blindara el acuerdo frente a un eventual cambio de mayoría parlamentaria. El punto esencial, acordado en Oslo, era el siguiente: «El Gobierno español respetará las decisiones que sobre su futuro adopten libremente los ciudadanos vascos. Dichas decisiones deberán ser adoptadas en ausencia de cualquier tipo de violencia o coacción, respetando las normas y procedimientos legales, los métodos democráticos y los derechos y libertades de los ciudadanos». ${ }^{81}$

Rajoy no se mostró entusiasta ante el alto el fuego de ETA: «No es una renuncia a la actividad criminal. Nos impone las condiciones de siempre». ${ }^{82}$ Durante algún tiempo, sin embargo, muchos españoles tuvieron la esperanza de que, esta vez, fuera posible que ETA renunciara a las armas. En junio de 2006 Zapatero intervino en el Congreso de los Diputados para realizar la declaración institucional que se había acordado en los contactos con la banda. Anunció que el Gobierno iba a iniciar un diálogo con ETA, manteniendo «el principio irrenunciable de que las cuestiones políticas sólo se resuelven con los representantes legítimos de la voluntad popular»; expresó su disposición a respetar las decisiones que los ciudadanos vascos adoptaran libremente y en ausencia de todo tipo de violencia y coacción, y advirtió, por otra parte, que mantendría la vigencia de la Ley de Partidos. ${ }^{83}$

Batasuna, sin embargo, no quiso acogerse a esta ley y se mantuvo en la ile-

80 Aizpeolea, Luis R., El País, 10-6-2007.

81 Gara, 21-6-2007.

82 El País, 23-2-2006.

83 El País, 30-6-2006.

Pasado y Memoria. Revista de Historia Contemporánea, 9, 2010, pp 149-174 
galidad. A la propia ETA no le gustó que Zapatero no hubiese aludido a Navarra en su declaración y en julio comunicó al Gobierno que no estaba dispuesta a comenzar la negociación sobre los presos si antes no se ponía en marcha la negociación política en la mesa de partidos. Esta última no llegó a constituirse, pero hubo negociaciones para ponerla en marcha, en las que participó también el PNV. En septiembre PSE y PNV iniciaron contactos en Loyola con la ilegalizada Batasuna para avanzar hacia la formación de la mesa de partidos, pero en sucesivas reuniones sus representantes, Arnaldo Otegi y Rufino Etxevarría, elevaron sus exigencias al pretender que en el plazo de dos años se estableciera un órgano legislativo común de Navarra y Euskadi. Según El País, sus interlocutores se negaron a aceptarlo y las negociaciones quedaron interrumpidas en noviembre. ${ }^{84}$ Según un periodista vasco próximo al dirigente nacionalista Josu Jon Imaz, en las negociaciones de Loyola se planteó un principio de acuerdo que incluía una referencia a un órgano de cooperación entre Euskadi y Navarra, pero la ruptura se produjo cuando Otegi transmitió la exigencia de que en el plazo de dos años se celebrara un referendum para la unión de ambos territorios en el que los socialistas navarros habrían de comprometerse a propugnar el sí. ${ }^{85}$

Una versión de los contactos entre las delegaciones del Gobierno y ETA la publicó Gara en 2007, poco después de que ETA rompiera la tregua. Según la versión publicada por este diario, el primer encuentro tras el anuncio del alto el fuego se produjo en junio de 2006 a petición de ETA, que protestó porque se siguieran haciendo detenciones, se mantuviera a Batasuna en la ilegalidad y el Gobierno no hubiera avanzado hacia un "pacto de Estado» con el PP. Las siguientes reuniones no se produjeron hasta finales de septiembre, de nuevo por iniciativa de ETA, quien de nuevo protestó de que no se estuviera cumpliendo lo pactado, a lo cual replicaron los delegados del Gobierno denunciando los incumplimientos de la propia ETA, incluida la reactivación de la kale borroka y las cartas de extorsión a empresarios. En una reunión celebrada en octubre se estuvo cerca de la ruptura, pero se concertó una nueva cita para diciembre, que se produjo cuando las negociaciones de Loyola entre PSE, PNV y Batasuna estaban estancadas por el tema de Navarra, que ETA planteó de nuevo. Por su parte, los delegados del Gobierno ofrecieron concesiones en materia judicial y penitenciaria y se mostraron dispuestos a legalizar Batasuna si ésta lo solicitaba de acuerdo con la legislación vigente, pero no hubo acuerdo. ${ }^{86}$

En lo sustancial esa versión de Gara ha sido confirmada por Luis Azpiolea en

84 El País, 10-6-2007.

85 Aranberri, L. A., El Diario Vasco, 6-2-2008.

86 Gara, 22-6-2007.

Pasado y Memoria. Revista de Historia Contemporánea, 9, 2010, pp 149-174 
El País en un detallado análisis publicado en abril de 2011, basado en las actas de los encuentros de ETA con el Gobierno que fueron incautadas al dirigente etarra Javier López Peña, alias Thierry, y posteriormente filtradas a la prensa. Según esta fuente, el encuentro crucial fue el celebrado en diciembre de 2006 en Oslo, en el que a diferencia de las anteriores sesiones de negociación celebradas en junio y septiembre en Suiza, no estuvo presente Josu Ternera y la voz cantante la llevó Thierry, quien insistió en que antes de abordar cualquier otro tema el Gobierno debía aceptar la exigencia política de un estatuto único para Euskadi y Navarra, una imposición de ETA que había conducido ya al fracaso de las negociaciones de Loyola entre PSE, PNV y Batasuna. A la negativa del Gobierno ETA decidió responder con un nuevo atentado. ${ }^{87}$

El 30 de diciembre de 2006 los terroristas colocaron en la terminal T4 del aeropuerto de Barajas un potente explosivo que mató a dos ciudadanos ecuatorianos. De inmediato Zapatero declaró que había ordenado «suspender todas las iniciativas para desarrollar el diálogo», pero «suspender» no implicaba romper definitivamente la negociación. En realidad el presidente pareció considerar lo ocurrido como un «accidente» de aquellos que, según lo acordado en los contactos previos con ETA, se podían reconducir y no había asumido el fracaso del último encuentro con la banda en Oslo. Así es que el desencuentro entre PSOE y PP en materia antiterrorista, ya estimulado por la teoría de la conspiración sobre el 11-M que el segundo parecía asumir, alcanzó cotas elevadísimas. El 13 de enero de 2007 una masiva manifestación «por la paz, la vida, la libertad y contra el terrorismo» convocada por CC.OO. y UGT en Madrid, a la que el PP rehusó sumarse, se convirtió en una demostración de apoyo a Zapatero y de repudio a los populares. ${ }^{88} \mathrm{Y}$ a su vez, unos días después, otra manifestación contra el diálogo con ETA, convocada en Madrid por el Foro Ermua, dio ocasión a que muchos participantes lanzaran insultos contra el presidente: «Zapatero, embustero». ${ }^{89}$ Cuando semanas después el fiscal retiró la acusación contra Arnaldo Otegi por enaltecimiento del terrorismo, el secretario general del PP, Ángel Acebes, afirmó que se había pisoteado el Estado de derecho. ${ }^{90}$

Un claro indicio público de que el Gobierno no descartaba una reanudación de las negociaciones se tuvo con ocasión de las elecciones municipales de mayo de 2007, en las que el Gobierno y la fiscalía tomaron la salomónica decisión de impugnar ante el Tribunal Supremo casi la mitad de las candidaturas de ANV,

87 Azpiolea, Luis R., El País, 3-4-2011.

88 ABC, 14-1-2007.

89 El País, 4-2-2007.

90 El País, 22-3-2007.

Pasado y Memoria. Revista de Historia Contemporánea, 9, 2010, pp 149-174 
el partido que en esta ocasión representaba al entramado de ETA. El Supremo anuló las candidaturas impugnadas, pero no pudo hacer nada respecto a las no impugnadas, lo que abrió a ANV las puertas del Gobierno en 34 ayuntamientos vascos. ${ }^{91}$

Durante aquellos meses hubo contactos secretos para impulsar la negociación, que culminaron a mediados de mayo de 2007 en una ronda de encuentros entre delegaciones del PSOE y Batasuna y del Gobierno con ETA, por otro, que tuvo lugar en un país europeo. De las mismas fue excluido el PNV, cuyo presidente, Josu Jon Imaz, de un talante muy distinto al de su predecesor Arzalluz, se oponía a seguir negociando. Los primeros datos sobre estos encuentros los dio a conocer Gara después que ETA rompiera la tregua, pero sin mencionar a más participantes que Otegi. El obstáculo que llevó a la ruptura fue la cuestión política. ETA y Batasuna exigían la aprobación de un nuevo estatuto vasco que incluyera a Navarra y que preparara la autodeterminación, mientras que los socialistas se limitaron a ofrecer reformas estatutarias en las dos comunidades implicadas y la posibilidad de constituir en el futuro un órgano común intergubernamental entre ellas. ${ }^{92}$

Esta versión se puede ampliar mediante la información basada en las actas de Thierry que El País ha publicado en abril de 2011. La reunión entre las delegaciones del Gobierno y ETA tuvo lugar a mediados de mayo, de nuevo en Ginebra, esta vez con asistencia de sendos enviados del primer ministro británico, Tony Blair, y del Sinn Feinn, uno y otro favorables a que el modelo de paz irlandés se aplicara también al caso vasco. Una vez más Thierry exigió la unión de Euskadi y Navarra en el plazo de dos años (ETA parecía considerar que la gran diferencia entre su modelo de marcha hacia la independencia y el que pudiera emprender el PNV consistía en que Navarra se incorporara desde el primer momento), mientras que la delegación gubernamental pidió que ETA condenara el atentado de la T4 y se comprometiera públicamente al cese definitivo de la violencia. No hubo acuerdo y el 5 de junio de 2007 un comunicado de ETA anunció formalmente la ruptura de la tregua. ${ }^{93}$

ETA volvió a matar en diciembre de 2007, cuando asesinó en Francia a dos agentes de la Guardia Civil, pero nunca recuperó su capacidad anterior. 146 presuntos etarras fueron detenidos en España y el extranjero en 2004, 88 en 2005, 43 en 2006, el año de la tregua, y 125 en $2007 .{ }^{94}$ Su cúpula «política»

91 El País, 4-5-2007, 7-5-2007 y 17-6-2007.

92 Gara, 15-6-2007, 23-6-2007 y 24-6-2007.

93 Azpiolea, Luis R., El País, 3-4-2011.

94 El País, 20-2-2008.

Pasado y Memoria. Revista de Historia Contemporánea, 9, 2010, pp 149-174 
sufrió dos importantes caídas: en diciembre de 2004, en los primeros tiempos del Gobierno de Zapatero, fueron detenidos Mikel Albizu y Soledad Iparragirre, que llevaban diez años al frente de la banda, y en mayo de 2008 lo fue su sucesor Javier López Peña. ${ }^{95}$

En tanto la justicia seguía su curso. En febrero de 2006 el Tribunal Supremo adoptó una nueva doctrina, conocida como «doctrina Parot» por el apellido del etarra al que por primera vez se aplicó, por la que los delincuentes condenados por varios crímenes a más de treinta años, tendrían que cumplir treinta, en vez de los veinte que solían cumplir antes de la reforma del Código Penal. ${ }^{96}$ En enero de 2007 el Supremo declaró «organización terrorista» a Jarrai y elevó las penas que la Audiencia Nacional había impuesto previamente a sus dirigentes. ${ }^{97}$ A finales de ese año la Audiencia condenó por integración en organización terrorista a los dirigentes de Ekin, la coordinadora que había sucedido a KAS, lo que provocó una dura reacción del Gobierno vasco, que en una declaración oficial afirmó que la sentencia establecía «el delito de opinión» y hería a la democracia..$^{98}$ Aunque el Supremo redujo en mayo de 2009 sus penas, lo fundamental es que confirmó la ilicitud de Ekin, de su predecesora KAS y de Xaki, el aparato de relaciones internacionales de ETA. ${ }^{99}$ Por su parte el juez Garzón suspendió en febrero de 2008 las actividades de ANV y PCTV, tapaderas electorales de Batasuna en los últimos años, cuya ilegalidad fue confirmada meses después por el Supremo. ${ }^{100}$ Por último, la Audiencia Nacional condenó en septiembre de ese año a los dirigentes de Gestoras por Amnistía por formar parte de una organización terrorista. ${ }^{101}$

En este nuevo entorno, en el que tras el paréntesis de la frustrada negociación con ETA estaban dando sus frutos las iniciativas legislativas y judiciales adoptadas en los años de gobierno de Aznar, no fue difícil restablecer el consenso antiterrorista entre los dos grandes partidos españoles. En julio de $2008 \mathrm{Za}$ patero y Rajoy se reunieron y acordaron un pacto que implicaba la recuperación de la unidad en la lucha contra el terrorismo. En particular se reafirmó que el Gobierno no pagaría ningún precio político por el final de ETA. ${ }^{102}$ La nueva firmeza se manifestó en las elecciones autonómicas de febrero de 2009, en las que la justicia anuló todas las listas filoetarras. Esto implicó un cambio de mayoría

95 El País, 19-4-2009.

96 El País, 21-2-2006.

97 El País, 20-1-2007.

98 El País, 20-12-2007 y 21-12-2007.

99 El País, 27-5-2009.

100 El País, 9-2-2008, 17-9-2008 y 19-10-2008.

101 El País, 18-9-2008.

102 El País, 24-7-2008 y 25-7-2008.

Pasado y Memoria. Revista de Historia Contemporánea, 9, 2010, pp 149-174 
parlamentaria e hizo posible la formación de un gobierno socialista, encabezado por Patxi López, con el apoyo externo del PP. Con ello, un nuevo clima político se estableció en Euskadi.

A partir de la ruptura de la tregua en 2007, acorralada por la justicia en España y en Francia, con continuas caídas de sus dirigentes, ilegalizadas las entidades de su trama y muy reducido el apoyo popular de que antaño gozó en el País Vasco, ETA ha perdido la relevancia política que sus asesinatos le dieron durante décadas. El ministro del Interior Alfredo Pérez Rubalcaba, que en su primera etapa estuvo llamado a gestionar la tregua y la negociación, ha pasado a gestionar el éxito policial contra ETA. Y en esas circunstancias el debate político sobre el terrorismo se ha calmado. Salvo alguna voz aislada, como la del presidente del PSE Jesús Eguiguren, nadie defiende en las filas socialistas la utilidad de reabrir la vía negociadora, así es que el tema ya no constituye un argumento relevante para la oposición conservadora, aunque el ex ministro Mayor Oreja sigue insistiendo, sin ofrecer pruebas, en que hay contactos entre el Gobierno y la banda.

El nuevo consenso se puso de manifiesto cuando el 5 de septiembre de 2010 hizo saber en un video difundido por la BBC que desde hacía algunos meses había tomado la decisión «de no llevar a cabo acciones armadas ofensivas». Este nuevo anuncio de tregua tuvo una gran cobertura mediática pero no generó apenas debate porque con la banda tan debilitada y tras la frustrante experiencia de la negociación anterior, la tentación de hacer concesiones resultaba mínima. A pesar de los matices esperables de acuerdo con la orientación de cada periódico, lo que llamaba la atención en los editoriales de la prensa madrileña del día 6 era la unanimidad de fondo. ABC observaba que de ETA es «vano esperar nada» y Público hacía notar que «su credibilidad tras la voladura del anterior proceso de paz está a cero». El País atribuía la debilidad de ETA a «la firmeza judicial contra el brazo político, avalada en términos inequívocos por Estrasburgo; la eficacia policial contra ETA; la negativa a negociar compartida por Gobierno y oposición; la desconfianza hacia ese mundo de un PNV escarmentado». Así es que, proclamaba El Mundo: «El Estado de Derecho debe seguir combatiendo policialmente a ETA, sin pagar ningún precio político por su desaparición». De hecho ésa fue la respuesta oficial, así es que La Razón pudo manifestar satisfecha que «la reacción de los grandes partidos y del Gobierno» había sido «ejemplar». Únicamente se desmarcó por la extrema derecha La Gaceta, que en su editorial pretendía entrever en el comunicado etarra que el Gobierno ponía «alfombra roja a los asesinos». ${ }^{103}$

Sin embargo el legado de períodos más complejos no ha desaparecido del

103 ABC, Público, El País, El Mundo, La Razón y La Gaceta, 6-9-2010. 
todo. El 4 de mayo de 2006, pocas semanas después de que ETA hubiera anunciado la tregua, un soplo al dueño del bar Faisán en Irún, implicado en la trama de extorsión de ETA, impidió las detenciones ordenadas por el juez Grande Marlaska. Esas detenciones se produjeron poco después, el 20 de junio, pero lo grave fue que el origen del soplo había sido policial, lo que ha conducido a la imputación de mandos policiales, incluido el entonces Director General de la Policía, y el 24 de enero de 2011 el juez Pablo Ruz decidió la incoación de un sumario «por presuntos delitos de revelación de secretos y colaboración con organización terrorista». ${ }^{104}$ Dos meses después el tema ha adquirido mayor relevancia mediática por la filtración de las actas de las reuniones entre representantes del Gobierno y de ETA, incautadas cuando López Peña fue detenido en mayo de 2008, en las que constaba como en la reunión del 22 de junio de 2006 los primeros lamentaron que no se hubieran podido impedir las detenciones de los miembros de la red Faisán: «son un accidente grave pero no lo hemos podido parar». ${ }^{105}$ Ésta y otras revelaciones han engendrado un enconado debate y el PP ha pedido la dimisión de Rubalcaba, ministro del Interior cuando ocurrieron los hechos. Estamos sin embargo ante un debate sobre responsabilidades por hechos pasados y no sobre la política antiterrorista de hoy, acerca de la que se mantiene el consenso.

\section{Conclusiones}

Como en etapas anteriores, el debate sobre la política antiterrorista ha jugado un papel muy relevante en la vida pública española durante las presidencias de Aznar y Zapatero. El punto de inflexión decisivo se produjo en la segunda legislatura de Aznar cuando, tras la ruptura de la primera tregua por parte de ETA, se adoptó la opción de poner fin a la tolerancia frente a todas las entidades del entramado etarra que no empuñaban directamente las armas, una iniciativa en la que el Gobierno de Aznar contó con el pleno apoyo de la oposición socialista, aunque recibió fuertes críticas por parte del nacionalismo vasco. Los atentados del 11-M dieron en cambio lugar a una campaña mediática, a la que se sumó el PP, cuya irresponsabilidad tiene pocos paralelos en la historia de las democracias occidentales, ya que se emplearon indicios irrelevantes para poner en cuestión la versión que sobre la base de pruebas abrumadoras estableció la investigación policial y asumieron luego los tribunales, primero la Audiencia Nacional y luego el Tribunal Supremo. Y en esas circunstancias, la decisión de Zapatero de iniciar

104 Juzgado Central de Instrucción n. ${ }^{o}$ 5, Madrid, Auto Incoación Sumario, 24-1-2011.

105 El Mundo, 28-3-2011; El País, 29-3-2011.

Pasado y Memoria. Revista de Historia Contemporánea, 9, 2010, pp 149-174 
un nuevo proceso de negociación con ETA generó un fuerte enfrentamiento en la opinión pública española.

Posteriormente el hundimiento de ETA y la disminución del peligro yihadí han llevado a una situación en que la amenaza terrorista ha dejado de constituir una de las principales preocupaciones de los españoles. La experiencia del caso Faisán pone de manifiesto los peligros en que incurre un Gobierno democrático cuando entra en negociaciones con una banda como ETA, pues aunque sea con el loable propósito de poner fin a una amenaza terrorista ello puede implicar actuaciones de difícil encaje en la legalidad. Sin embargo, a pesar de sus posibles repercusiones jurídicas y políticas, difíciles de prever cuando esto se escribe, el caso Faisán es un tema menor. Las grandes cuestiones que suscita la experiencia histórica aquí analizada son, a mi juicio, tres. En primer lugar, la eficacia de una política antiterrorista que enfrentada a un desafío de la magnitud que ha llegado a tener el de ETA no se ha limitado a la detención de los miembros armados de la banda, sino que ha buscado la desarticulación de todo su entramado de apoyo. Éste ha sido, en mi opinión, un logro indiscutible, de la segunda legislatura de Aznar, basado en el consenso antiterrorista de los dos grandes partidos. En segundo lugar, el peligro que para la racionalidad del debate político tiene la difusión de teorías de la conspiración infundadas, pero basadas en un fuerte impacto emocional, como las que surgieron a raíz de los atentados del 11-M. Y en tercer lugar la difícil cuestión del papel que en el fin de un fenómeno terrorista puede jugar la negociación con los propios terroristas, algo siempre condenable desde la pureza de los principios éticos pero en ocasiones útil en el bajo mundo de la realidad, como se ha demostrado en Irlanda. La negociación del Gobierno de Zapatero con ETA en 2006 puede verse como un error que retrasó el final de la banda armada o como un elemento que ha contribuido al distanciamiento de Batasuna, decepcionada por la intransigencia de ETA que le condenaba al ostracismo, y por tanto a la actual debilidad extrema de la banda. El debate acerca de cuál de ellas es la interpretación adecuada es hoy político pero es probable que en adelante se convierta en un debate historiográfico. 